\title{
A FORMAÇÃO DO PROFESSOR ESPECIALIZADO EM DEFICIÊNCIA INTELECTUAL NO PROGRAMA REDEFOR: CONTRIBUIÇÕES DO ESTÁGIO E DA ABORDAGEM CCS
}

\author{
Paula Mesquita Melques, Naiara Chierici da Rocha, Elisa Tomoe Moriya Schlünzen \\ ${ }^{1}$ Universidade Estadual Paulista - UNESP, Programa de Pós Graduação em Educação, Presidente Prudente, SP. E-mail: \\ paulamelques@gmail.com
}

\section{RESUMO}

A matrícula do Público Alvo da Educação Especial no ensino regular tem aumentado significativamente e as escolas tem enfrentado desafios para se adaptar e atender a diversidade dos seus alunos. Para que a escolarização do estudante com DI seja possível, o professor especializado tem papel fundamental. Diante disso, o presente artigo tem como objetivo discutir como o estágio e a abordagem Construcionista, Contextualizada e Significativa (CCS) podem contribuir com a formação desse profissional. Para tanto, a partir de uma abordagem qualitativa, foram utilizados dados extraídos do Ambiente Virtual de Aprendizagem Moodle do curso de especialização em Educação Especial na área da DI. Como resultados, os cursistas relatam a mudança de concepção em relação à DI, a indissociação entre a avaliação e o planejamento, a importância de reconhecer as potencialidades dos alunos com DI e a necessidade de articulação entre o trabalho do professor especializado e o professor da sala comum.

Palavras-chave: Abordagem CCS, Professor especializado, Deficiência Intelectual, Formação em serviço, Estágio.

\section{THE TEACHER TRAINING SPECIALIZED IN INTELLECTUAL DISABILITY IN REDEFOR PROGRAM: INTERNSHIP CONTRIBUTIONS AND CCS APPROACH}

\begin{abstract}
The Target Audience of Special Education Students enrollments in regular school has increased significantly and the school has been facing challenges to adapt and to attend student's diversity. To make possible the education of DI students, the specialized teacher has essential role. The purpose of this article is to discuss how teacher training and Constructionist, Contextual and Meaningful (CCM) approach may contribute with the education of this professional. In a qualitative approach, Virtual Environment Leaning Moodle of specialization course in Special Education data were used. As a result, the course participants report the change of design in relation to ID, the indissociation between evaluation and planning, the importance of recognizing the potential of students with ID and the necessity for coordination work between the specialized teacher and the teacher.
\end{abstract}

Keywords: CCS Aproach, Specialized teacher, Intellectual Disability, In-service training, Internship. 


\section{INTRODUÇÃO}

Com o direito à educação garantido a todos pela Lei de Diretrizes e Bases da Educação Nacional (LDBEN 9394/96), a matrícula no ensino regular dos Estudantes Público Alvo da Educação Especial (EPAEE) - os com deficiência, Transtorno Global do Desenvolvimento e Altas Habilidades/Superdotação - tem aumentado significativamente nos últimos anos. No entanto, para a escola tem sido um grande desafio se adaptar para receber todos os alunos. Embora a diversidade e a individualidade estejam presentes mesmo entre os alunos sem deficiência, as inserções dos EPAEE na escola comum evidenciam as diferenças e as necessidades de adaptação no que concerne a aspectos arquitetônicos, atitudinais, estruturais, metodológicos, curriculares, entre outros.

Diante disso, o presente artigo tem como foco a DI, bem como a formação de professor para esta especificidade da Educação Especial. Assim, para que o aluno com DI tenha o seu direito à educação respeitado, além de estar incluído na classe comum, no contraturno, deve frequentar o Atendimento Pedagógico Especializado (APE), conforme estabelecido na Resolução do estado de São Paulo SE no 61, de 11/11/2014, com a atuação do professor especializado em DI na sala de recursos desta área. O professor especializado tem papel fundamental no trabalho junto ao professor da sala comum, uma vez que as atribuições desse professor a partir da Resolução concernem à articulação e a orientação na criação de estratégias, recursos de acessibilidade e metodologias entre a sala de recursos e a sala comum. Nesse direcionamento, os serviços prestados pelo APE devem propor práticas colaborativas com o objetivo de melhorar a qualidade da oferta da Educação Especial na rede estadual, favorecendo a inclusão escolar.

Para tanto, é necessário formar os professores e gestores interessados em atuarem na sala de recursos de DI como professor especializado. Nessa perspectiva, o curso de especialização semipresencial do Programa Rede São Paulo de Formação Docente (Redefor) em Educação Especial na área de Deficiência Intelectual será abordado neste trabalho. Com isso, o objetivo é discutir como o estágio e a abordagem Construcionista, Contextualizada e Significativa (CCS) (SCHLÜNZEN, 2000) podem contribuir com a formação desse profissional.

\section{METODOLOGIA}

Esta pesquisa está vinculada ao Programa Redefor Educação Especial e Inclusiva intitulada "Rede de educação inclusiva: Formação de Professores nos âmbitos de Pesquisa, Ensino e Extensão", aprovada pelo Comitê de Ética em Pesquisa (CAAE), da Faculdade de Ciências e 
Tecnologia (FCT), UNESP, campus de Presidente Prudente, SP, sob o no 26341614.3.0000.5402, cujo parecer no 173.558 é datado de 07 de dezembro de 2012.

Como afirma Imbernón (2010, p. 53), "historicamente, os processos de formação foram realizados para dar solução a problemas genéricos, uniformes, padronizados". Este tipo de formação não considera as especificidades da formação em serviço e o contexto do professor, e este não atribui significado ao que está aprendendo, não articulando teoria e prática. Com isso, o professor não consegue solucionar os desafios do cotidiano escolar e refletir sobre a sua prática, especialmente após concluir a formação. Tendo como foco o professor especializado em DI, os desafios são ainda maiores.

Considerando essas premissas, apresenta-se o curso de especialização em Educação Especial, na área de DI, do programa Redefor Educação Especial e Inclusiva, oferecido na modalidade semipresencial, a partir da parceria entre Secretaria Estadual da Educação de São Paulo, Escola de Formação e Aperfeiçoamento dos Professores, Pró-Reitoria de Pós Graduação e Núcleo de Educação a Distância da Universidade Estadual Paulista (NEaD/Unesp).

Em relação à concepção pedagógica, os idealizadores do curso adotaram a abordagem Construcionista, Contextualizada e Significativa (CCS) (SCHLÜNZEN, 2000), por acreditarem que esta é a maneira mais adequada para a formação dos educadores em serviço. De acordo com Schlünzen (2005) apud Schlünzen et. al (2011, p. 235), a abordagem CCS

possibilita o afloramento do interesse do estudante, motivando-o a explorar, a pesquisar, a descrever, a refletir, a depurar suas ideias, com a mediação do professor, permitindo desenvolver, por meio do uso das Tecnologias Digitais de Informação e Comunicação, um projeto que faz parte da sua vivência e contexto.

A abordagem CCS permeia todo o curso. O designer educacional - profissional responsável pelo processo de produção pedagógica do curso - em conjunto com os professores autores das disciplinas e especialista do curso, elaboram materiais e atividades de modo que cada cursista possa realizá-las considerando o seu contexto escolar. Assim, as disciplinas são pensadas de forma articulada e com atividades que almejam que o cursista explore o seu contexto, pesquise e reflita como contribuir com tal cenário e depure as suas ideias por intermédio do tutor on-line, num processo espiral.

Nessa perspectiva, podem ser citadas como exemplo algumas disciplinas que possuem carga horária de estágio. No estágio, o cursista coleta os dados dentro da própria prática e sistematiza-os a partir da atividade realizada no AVA. As disciplinas que contam com o estágio são as disciplinas de Avaliação, Planejamento de Ensino Individualizado (PEI) (na legislação estadual 
atual, Plano de Atendimento Individualizado (PAI)), Tecnologia Assistiva, e ainda, Ensino Colaborativo, todas com foco no aluno com DI.

A partir da articulação entre as disciplinas, na primeira disciplina com estágio, o cursista avaliou um aluno com DI do seu contexto a partir do Referencial de Avaliação Pedagógica e da fundamentação teórica e prática da disciplina. Na disciplina que abordou o PEl, o cursista elaborou um plano de atendimento individualizado para o mesmo aluno já avaliado, de maneira a garantir o ensino de conteúdos específicos, utilização de estratégias e recursos diferenciados, não existentes na classe comum, que são fundamentais para assegurar a sua aprendizagem. Na disciplina que teve como tema central a Tecnologia Assistiva, foi possível explorar a escola em busca de recursos que pudessem ser utilizados com todos os alunos, inclusive os com DI, além de refletir sobre estratégias de ensino inclusivas. Por fim, na disciplina sobre Ensino Colaborativo, foi possível investigar as necessidades da escola em relação à inclusão de estudantes com DI e, a partir disso, planejar estratégias de Ensino Colaborativo que pudessem contribuir para solucionar ou amenizar os desafios vivenciados pela escola.

Cabe destacar ainda que não só as disciplinas que possuem carga horária de estágio tiveram atividades nas quais os cursistas puderam trazer dados da própria prática. O delineamento pedagógico de todo o curso contemplou questionamentos e propostas que instigassem os cursistas a pensar sobre o que vivenciam no seu contexto, partindo assim da experiência deles para a sistematização e formalização dos conceitos, e ainda, trazendo para o coletivo tanto as dificuldades enfrentadas, como também as estratégias utilizadas a fim de construir uma escola mais inclusiva.

A partir de uma abordagem qualitativa, foram utilizados dados extraídos do Ambiente Virtual de Aprendizagem (AVA) Moodle do curso explanação dos resultados.

\section{RESULTADOS}

O curso de especialização em Educação Especial na área da DI está na fase final, na etapa de elaboração de conclusão do Trabalho Acadêmico. Estão sendo realizadas avaliações estatísticas desde o início do curso por uma equipe especializada e, no presente trabalho, são utilizados trechos extraídos de atividades realizadas na ferramenta Fórum de discussão do AVA a fim de relacionar, qualitativamente, as percepções dos cursistas com os pressupostos teóricos apresentados.

O primeiro depoimento tem como principais pontos a mudança de concepção sobre a DI e a necessidade do envolvimento de todos os profissionais da escola. No ensino dos alunos com DI, 
é frequente observar que os professores não acreditam nas potencialidades deste público e a gestão solicita que seja atribuída a nota mínima para aprovação, independente do que esses alunos fazem na sala de aula e como fazem, sem orientar os professores sobre como podem oportunizar o desenvolvimento do aluno com DI, como observado na pesquisa de Melques (2013). A partir do depoimento seguinte, observa-se os pontos destacados anteriormente:

[...] minha concepção de Deficiência Intelectual era de que o aluno não conseguia aprender conteúdos específicos de cada disciplina porque era limitado e pensava que essa dificuldade, muitas vezes, era o limite e que não poderia haver uma aprendizagem após esse "limite". [...] o desenvolvimento do aluno com Deficiência Intelectual engloba muitas possibilidades, uma vez que ocorra a adaptação curricular, o acolhimento, a construção de situações de aprendizagem de acordo com os conhecimentos prévios e envolvendo os interesses destes, acredito ser possível efetivar a aprendizagem. Para que a escola tenha uma cultura inclusiva, gestores, professores, alunos e comunidade devem estar comprometidos com uma educação de qualidade e que haja o respeito com as diversidades (Cursista de DI, informação pessoal, grifo nosso) $)^{1}$.

Em oposição às concepções iniciais apresentadas, "o ensino deve propiciar ao estudante o acesso a níveis mais elevados de conhecimento e pensamento, ou seja, ao aprender ele se desenvolve e ao se desenvolver são criadas novas possibilidades para aprender" (OLIVEIRA, 2014, $s / p)$. A partir dessas contribuições de Oliveira, emerge a necessidade de se refletir sobre o modo como se planeja e executa a educação formal para o estudante com DI, tanto na classe comum quanto na sala de recursos.

Os próximos depoimentos apresentam relatos em relação ao estágio. A seguir, o cursista destaca a dificuldade que a equipe escolar possui em valorizar o que o aluno sabe, a importância da avaliação contínua, e ainda, a indissociação entre avaliação e planejamento.

A experiência de estágio permitiu refletir sobre as dimensões indissociáveis entre avaliação pedagógica e plano de ensino, além de evidenciar que o sucesso em sala de aula não é contemplado por muitos educadores devido à falta de entendimento sobre esta importância, não preparando suas aulas para que todos os alunos tenham diferentes possibilidades educacionais. Foi notável a dificuldade da equipe classe falar sobre o aluno, pois a maioria não sabe em que contextos os alunos estão inseridos e quais objetivos pretendem alcançar devido à falta de levantamento de dados sobre as habilidades já desenvolvidas, pois há registros somente daquilo que o aluno não saber fazer. (Cursista de DI, informação pessoal, grifo nosso).

\footnotetext{
${ }^{1}$ Todos os depoimentos de cursistas são do programa Rede São Paulo de Formação Docente Educação Especial e Inclusiva por SECRETARIA DA EDUCAÇÃO DO ESTADO DE SÃO PAULO [SEESP]. UNIVERSIDADE ESTADUAL PAULISTA [UNESP]. Núcleo de Educação a Distância [NEaD]. São Paulo: Ambiente Virtual de Aprendizagem Moodle Unesp [Edutec], 2014. Acesso restrito.
} 
Como observado, o depoimento anterior apresenta a fragmentação na formação dos sujeitos da escola e na prática cotidiana. A partir do estágio, o cursista teve a oportunidade de refletir sobre a própria prática confrontando-se com os problemas enfrentados no cotidiano escolar. A seguir, o cursista também destaca a importância do planejamento em consonância com a abordagem CCS - a importância de explorar, pesquisar, descrever, refletir e depurar as ideias partindo do que o aluno já sabe e sistematizando os conceitos. Para que o professor tenha essa concepção, é necessário ser formado para tanto.

[...] No entanto, o estágio reforçou a ideia de que precisa planejar, traçar objetivos a serem alcançados a partir de um ponto também pré-fixado, considerando o que o aluno já possui de conhecimento prévio, o que lhe é ensinado nesse espaço de tempo e seu avanço (Cursista de DI, informação pessoal, grifo nosso).

Para que seja feito o planejamento, a avaliação é fundamental por permitir "compreender as possibilidades e necessidades dos estudantes e, a partir daí, refletir sobre os modos de ensinar, sobre as estratégias de ensino ou a disponibilização de recursos que propiciem sua aprendizagem e, consequentemente, seu desenvolvimento" (OLIVEIRA, 2014, s/p).

Além da importância do planejamento individualizado, outros elementos fundamentais são destacados no depoimento a seguir. Um dos principais pontos é o "aprender a aprender com os alunos", pois não há uma receita de como incluir.

O estágio é essencial para a formação do aluno/ professor, pois relaciona o conhecimento teórico com a prática. [...] "aprendemos a aprender" com nossos alunos. [...]. Com a nova legislação, vejo que melhorou seus objetivos, pois adequaram seus tópicos sendo ampliados e compartilhados com toda a equipe que trabalha com esse aluno. Com ele pude planejar e desenvolver um plano de aula rico em ações que puderam contemplar não só o aluno da educação especial, mas todos os alunos presentes na sala, havendo a interação da sala de aula comum com a sala de recursos. Em minha escola não houve aspectos que dificultassem os trabalhos da sala de recurso com a sala comum, uma vez que os professores são solidarios e parceiros nessa tarefa [...] (Cursista de DI, informação pessoal, grifo nosso).

Esse depoimento chama a atenção para o fato de que o ensino colaborativo, segundo Machado e Almeida (2010), proporciona novos espaços e novas formas de aprendizagem, visto que possibilita apoio aos estudantes PAEE, ao trabalho pedagógico realizado e à criação de estratégias de ensino. Desse modo, concorda-se com Cook e Friend (1995), pois trabalhar colaborativamente é exercer um trabalho com parcerias para um bem comum, no 
desenvolvimento de um ensino mais adequado para se potencializar a aprendizagem e socialização do estudante com deficiência.

\section{DISCUSSÃO}

Diante das perspectivas teóricas e dos resultados apresentados, entende-se que o ensino colaborativo parte do princípio da existência de uma parceria entre os professores do ensino regular e da educação especial. Essa parceria e colaboração se configuram como uma estratégia para articular os serviços da educação especial com o ensino regular almejando favorecer a aprendizagem dos estudantes PAEE considerando o mesmo currículo para todos.

Essa parceria é fundamental para propiciar melhor planejamento, avaliação e organização de recursos de ensino para os estudantes EPAEE. A partir dessa concepção, destaca-se, segundo (SILVA, 2007), que essa troca se torna possível e eficiente, uma vez que os professores da sala comum são especialistas em conteúdos específicos de uma determinada disciplina escolar, e os professores da Educação Especial são especialistas em avaliação e estratégias específicas dessa modalidade de ensino.

Para tanto, o professor precisa ter uma formação adequada e coerente com essa proposta de atuação, que considere como alguns dos pontos primordiais a avaliação do aluno com DI, o plano de atendimento individualizado e o ensino colaborativo, a fim de que o professor possa conhecer os seus alunos, elaborar estratégias de ensino adequadas, avaliar continuamente e trabalhar colaborativamente com a comunidade escolar de maneira que todos, e não só o professor especializado, sejam responsáveis pela educação dos alunos.

\section{CONSIDERAÇÕES FINAIS}

O presente artigo teve como objetivo apresentar a importância da abordagem CCS e da realização do estágio dentro desta abordagem para a formação em serviço do professor especializado em DI.

Como discutido, os desafios enfrentados pela escola para se adequar e incluir a todos os alunos, inclusive os com deficiência, são grandes e, tratando-se da DI, são ainda maiores. Para que a inclusão dos alunos com DI seja possível e aconteça, é preciso que o professor possua formação adequada e que ele trabalhe colaborativamente com toda a escola e, em especial, com o professor especializado, partindo da ideia de que os EPAEE são de responsabilidade de toda a escola e de que estes professores possuem papéis diferentes na escolarização do aluno. 
Conforme observado nos trechos extraídos do AVA, os cursistas relatam a mudança de concepção em relação à conceituação da DI e ao desenvolvimento dos alunos com essa deficiência, a indissociação entre a avaliação e o planejamento, a importância de valorizar o contexto do aluno e o que ele já sabe, assim como focar nas potencialidades dos alunos, e também, a necessidade de articulação entre o trabalho do professor especializado e o professor da sala comum.

Assim, buscou-se relacionar os pressupostos teóricos apresentados em relação à formação em serviço do professor e a concepção pedagógica do curso a partir das vivências dos cursistas. Foi apresentado um caso particular com aspectos específicos do Estado de São Paulo, mas acredita-se que poderiam ser obtidos resultados satisfatórios em diferentes contextos.

\section{REFERÊNCIAS}

BRASIL. Ministério da Educação. Lei n. 9.394, de 20 de dezembro de 1996. Estabelece as diretrizes e bases da educação nacional. Diário Oficial da União, Brasília, DF, Seção 1, n. 248, p. 207, 23 dez. 1996.

COOK, L.; FRIEND, M. Co-teaching: Guidelines for creating effective practices. Focus on Exceptional Children, no 28, pp, 1-16, 1995.

IMBERNÓN, F. Formação continuada de professores. Tradução Juliana dos Santos Padilha. Porto Alegre: Artmed, 2010. 120 p.

MACHADO, A. C.; ALMEIDA, M. A. A. Parceria no contexto escolar: uma experiência de ensino colaborativo para educação inclusiva. Rev. Psicopedagogia, v. 27, n. 84, 2010, p. 344-351.

MELQUES, P. M. O uso de objetos educacionais no ensino de Física e suas relações com o processo de inclusão. 2013. 125 f. Dissertação (Mestrado em Educação) - Faculdade de Ciências e Tecnologia, Unesp, Presidente Prudente. 2013. Disponível em:

http://www2.fct.unesp.br/pos/educacao/teses/2013/ms/paula.pdf. Acesso em: 20 mai. 2015.

OLIVEIRA, A. A. S. Da avaliação ao planejamento: foco na ação do professor especializado. São Paulo: AVA Moodle Unesp [Edutec], 2014. No prelo. Disponível em:

<www.edutec.unesp.br/moodle>. Acesso em: 20 mai. 2015.

OLIVEIRA, A. A. S. Avaliação pedagógica, deficiência intelectual e os processos de ensino. São Paulo: AVA Moodle Unesp [Edutec], 2014. No prelo. Disponível em:

<www.edutec.unesp.br/moodle>. Acesso em: 20 mai. 2015.

SÃO PAULO (Estado). Resolução SE no 61, de 11 de novembro de 2014.

SCHLÜNZEN, E. T. M. Mudanças nas Práticas Pedagógicas do Professor: criando um ambiente construcionista contextualizado e significativo para crianças com necessidades especiais físicas. 
São Paulo, 2000. Tese (Doutorado em Educação: Currículo). Pontifícia Universidade Católica de São Paulo (PUC_SP).

SCHLÜNZEN, E. T. M.; SCHLÜNZEN, K. J.; SANTOS, D. A. N. Formação de professores, uso de Tecnologias Digitais de Informação e Comunicação e escola inclusiva: possibilidades de construção de uma abordagem de formação Construcionista, Contextualizada e Significativa. Revista Pedagógica - UNOCHAPECó - Ano 14 - n. 26 vol.01 - jan/jun 2011. Disponível em:

<http://bell.unochapeco.edu.br/revistas/index.php/pedagogica/article/view/1272/702>. Acesso em: 10 abr. 2015.

SILVA, A. M. da. Buscando componentes da parceria colaborativa na escola entre família de crianças com deficiência e profissionais. 130f. Dissertação de Mestrado - UFSCar: São Carlos, 2007. 